\title{
Pediatric ambulatory blood pressure monitoring: diagnosis of hypertension
}

\author{
Abanti Chaudhuri \\ Received: 8 January 2013 /Revised: 5 March 2013 /Accepted: 5 March 2013 /Published online: 17 April 2013 \\ (C) IPNA 2013
}

\begin{abstract}
Pediatric hypertension (HTN) is a growing concern and should be diagnosed and treated aggressively to reduce the global disease burden. Ambulatory blood pressure monitoring (ABPM) is a useful clinical tool providing a more accurate description of the patient's blood pressure (BP) than office BP measurements, and can be considered the "gold standard" in the evaluation of the pediatric patient with a concern for HTN. The American Heart Association have suggested criteria for diagnosing ambulatory HTN, and research continues into further clarification of how to best utilize the large volume of data obtained from an ABPM report. ABPM has some limitations; however, the advantages far outweigh these. Routine use of ABPM is recommended among clinicians to better evaluate and assess the severity of a child's HTN, and for proper management in order to prevent target organ damage and the resulting sequelae, thereby reducing the burden of cardiovascular risk in hypertensive children and adolescents.
\end{abstract}

Keywords ABPM · Pediatric hypertension · Ambulatory blood pressure monitoring

The epidemic of obesity along with hypertension (HTN) and cardiovascular disease is a major growing contributor to global disease burden $[1,2]$. The prevalence of HTN and pre-HTN in children and adolescents has continued to increase over the last decade, to nearly $4 \%$ and $10 \%$ respectively [3]. Pediatric HTN remains one of the strongest predictors of adult HTN [4], which significantly increases the cardiovascular mortality risk in adults $[5,6]$. The prevalence of adult HTN and the resulting sequelae will continue

A. Chaudhuri $(\bowtie)$

Division of Nephrology, Department of Pediatrics, Stanford

University, G306, 300 Pasteur Drive,

Stanford, CA 94305, USA

e-mail: abanti@stanford.edu to increase further unless there is more aggressive screening, diagnosis, and treatment of HTN in children.

Although it is critically important to identify young hypertensive patients who need intervention, HTN and preHTN are frequently undiagnosed in pediatric populations [7]. Measuring blood pressure (BP) is difficult in children. $\mathrm{BP}$ levels vary on a minute-to-minute basis in response to a variety of physiological and environmental stimuli, which also makes BP measurement challenging. Ambulatory BP monitoring (ABPM) may overcome these challenges and help to properly characterize BP level and variability for better risk stratification and prediction of cardiovascular disease outcomes. ABPM uses a portable automated BP device that provides multiple BP measurements during regular activities throughout the day in the home (and school) environment and is the only method that allows BP measurement during sleep; therefore, ABPM is felt to provide a more accurate description of the patient's BP than office BP measurements, also eliminating the possibilities of improper technique and observer bias. Use of ABPM with established norms has allowed confirmation of true HTN even in children as young as 5 years old. White-coat HTN (WCH) is extremely common in children with incidence exceeding $40 \%[8,9]$. ABPM is especially useful, and the only available method, to identify $\mathrm{WCH}$ in children who are anxious in the medical setting, as well as those with masked HTN with normal BP in the clinic, but elevated BP by ABPM. The prevalence of masked HTN is $\sim 9 \%$ in the general pediatric population [10] and can be as high as $38 \%$ in children with chronic kidney disease [11]. ABPM also makes the diagnosis and treatment of nocturnal HTN possible, providing important information about the health of the cardiovascular system during sleep. ABPM HTN is associated with left ventricular hypertrophy (LVH) $[12,13]$ and progression to end-stage renal disease in children who have chronic kidney disease [14]. The use of ABPM to manage HTN has been shown to prevent progression of carotid intima-medial thickness in renal transplant recipients 
[15]. In addition, ABPM has been shown to be cost-effective in the evaluation of pediatric HTN [16]. Twenty-four-hour ABPM is now well established as a useful clinical tool in the evaluation of the pediatric patient who has elevated BP or is at risk of elevated BP, and application of ABPM will help clinicians improve BP control and reduce the burden of cardiovascular risk in hypertensive children and adolescents.

One important limitation of ABPM, however, is the lack of set guidelines for the diagnosis of HTN utilizing the large volume of data obtained from a single complete 24-h ABPM recording. An ABPM report often contains over 50 discrete $\mathrm{BP}$ readings taken at 20- to 30-min intervals while awake during the day and 30- to 60-min intervals at while asleep at night. At least one valid reading per hour, including during sleep, is necessary for a study to be considered complete [17]. Invalid readings are eliminated by the device software, and readings are then used to generate several key assessments, including average systolic BP (SBP), diastolic BP (DBP), and mean arterial pressure (MAP) during the daytime (awake BP) and night-time (sleep BP), and over the entire $24 \mathrm{~h}$. The readings are compared with established norms to determine associated BP load, defined as the percentage of valid ambulatory BP measures above the set 95th percentile of BP for age, gender, and height [18], which is also provided in the report for both day and night, and over the entire $24 \mathrm{~h}$. ABPM also provides information on nocturnal dipping, the normal reduction in BP that occurs with sleep, for both SBP and DBP. Recent research, in both adults and children, has begun to clarify the best approach to the application of an ABPM data set for interpretation of the HTN status of patients with elevated office BP. Diagnosis of ambulatory HTN and determination of the severity of BP elevation is made using both the office BP reading obtained by auscultation and the results of the ABPM study.

It is important to recognize that ABPM measurements made in the middle of a normal and active day with an oscillometric device tend to be higher than BP obtained with auscultation in seated children after $5 \mathrm{~min}$ of rest; hence, established ambulatory BP norms should be used as opposed to Task Force BP data [19]. The normative German ABPM data in the collaborative study by Soergel et al. [20] and the smoothed values by Wühl et al. [21] currently provide the reference values for interpretation of ambulatory BP in children. Separate tables for normative data are available for boys and girls by both age and height. It is preferred to use the tables for height, since height is an important determinant of BP in children, except in children less than $120 \mathrm{~cm}$ tall, in whom it may be necessary to use the tables by age, which do go down to 5 years [22]. The American Heart Association (AHA) updated these values and, in 2008, after some modifications of the work by Lurbe and colleagues [23], proposed the criteria for the classification of children as either normotensive or hypertensive by ABPM, as outlined in Table 1 [17]. Although the classification scheme in the AHA statement provides important information for the clinician to diagnose HTN, it does not provide guidance on how to analyze all the data obtained in an ABPM recording. Some questions still remain about the diagnosis of HTN by ABPM.

\section{Blood pressure load and mean}

Mean ABPM values can be assessed for the entire 24-h period or for the awake and asleep periods separately. Mean BP levels generated by the ABPM are compared with normative values to determine whether a subject's $\mathrm{BP}$ is normal or elevated. Mean BP alone does not provide information regarding BP variability, manifesting as large amplitude fluctuations above and below the 95th percentile value. BP load provides additional information on the true HTN burden in a specific patient. It has been suggested that both mean BP and BP load should be used to define ambulatory HTN. However, some patients with normal mean BP levels may have elevated BP loads. In adults, the BP load is more predictive of hypertensive end-organ injury than is mean $\mathrm{BP}$ [24], and normotension defined solely as mean 24-h BP less than the 95th percentile may be insensitive to the risk of hypertensive end-organ damage. BP loads in excess of $25 \%$ are typically considered elevated [24] and loads in excess of $50 \%$ have been demonstrated to be predictive of LVH [12]. Children with normal mean BP and elevated loads can be at risk of target-organ damage and may need antihypertensive therapy, even if they do not fit into the proposed criteria for the diagnosis of ambulatory HTN.

\section{Systolic and diastolic blood pressure}

Typical BP measurements include an SBP and a DBP value, representing the extremes of pressure fluctuation within the circulation during the cardiac cycle. There has been much debate about whether SBP or DBP HTN is more predictive of adverse cardiovascular outcomes. In routine clinical use of ABPM, it is apparent that some children have isolated DBP HTN. Based on AHA criteria, children with DBP HTN may be overlooked. It is likely that it is not a benign condition; isolated DBP HTN may be associated with a lower cardiovascular risk, but there is a high probability of transition to systolic-diastolic HTN $[25,26]$. DBP HTN on ABPM in children has been shown to potentially indicate the presence of underlying secondary causes of HTN [27], and has been shown to be associated with increased incidence of LVH in children on dialysis [28]. DBP load and mean are also important in diagnosing HTN in children, at least to filter out those who will require closer follow-up and 
Table 1 The American Heart Association (AHA)-suggested schema for the staging of ambulatory blood pressure (BP) levels in children (adapted from Urbina et al. [17], used with permission)

\begin{tabular}{llll}
\hline Classification & Clinic BP & Mean ambulatory SBP & SBP load, $\%^{\mathrm{a}}$ \\
\hline Normal BP & $<95$ th percentile & $<95$ th percentile \\
White coat HTN & $>95$ th percentile & $<95$ th percentile \\
Masked HTN & $<95$ th percentile & $>95$ th percentile & $<25$ \\
Pre-HTN & $>95$ th percentile & $<95$ th percentile & $>25$ \\
Ambulatory HTN & $>95$ th percentile & $>95$ th percentile & $25-50$ \\
Severe ambulatory HTN (at risk of end-organ damage) & $>95$ th percentile & $>95$ th percentile & $25-50$ \\
\hline
\end{tabular}

HTN hypertension, SBP systolic blood pressure

${ }^{a}$ Based on the National High Blood Pressure Education Program Task Force Standards

${ }^{b}$ Based on the ABPM values of Soergel et al. or the smoothed values of Wühl

not necessarily antihypertensive therapy. There is, however, a striking lack of variability of diastolic ambulatory BP in the normative data [29] and measurement of DBP by the oscillometric technique with ABPM is not as accurate as mercury measurements made using the auscultatory method. This makes the diagnosis of DBP HTN difficult.

\section{Mean arterial pressure}

Mean arterial pressure (MAP), the time-weighted average of BP during the entire cardiac cycle, is an excellent way to evaluate stress on the walls of the vessels and to assess perfusion pressure seen by target organs. MAP provides another indication of overall circulatory pressure load and has also been proposed to have prognostic relevance in assessing cardiovascular outcomes [14, 30, 31]. Treatment guided by ambulatory MAP was shown to reduce the rate of progression of CKD in the recently published ESCAPE trial, further highlighting the importance of this ambulatory BP parameter [14].

In the study by Suláková and Feber published in this issue of Pediatric Nephrology [32], the authors showed that the addition of MAP in the definition of ABPM hypertension in children would increase the detection of hypertension by $19 \%$. Suláková and Feber also point out that it may be more appropriate to utilize MAP to classify the results of ABPM studies, since this is the one BP parameter that is measured directly by the majority of devices used to perform ABPM in children, using the oscillometric technique, which directly measures MAP and back-calculates SBP and DBP using manufacturer-specific software algorithms. The calculated SBP and DBP values have been shown to vary significantly compared with SBP and DBP values obtained by auscultation. The inclusion of MAP into the ABPM definition may allow for earlier detection of BP abnormalities in children and prediction of cardiovascular outcome.

\section{Nocturnal blood pressure and dipping}

Currently, no guidance exists on how to evaluate isolated nocturnal HTN and declines in BP during sleep (dipping) on ABPM, both of which have significant prognostic implications. Nondipping describes a pattern of a blunted sleep-related fall in mean SBP or DBP $(<10 \%)$. Among adults, "nondippers" have been reported to be at greater risk of increased left ventricular mass index (LVMI) and morbid cardiovascular events [33]. Isolated nocturnal HTN and nondipping is reported to be highly prevalent in children with chronic renal insufficiency, on dialysis and after transplantation [28, 34]. Greater nocturnal SBP load on ABPM has been found to be highly specific for a secondary cause of HTN in children [27]. In addition, nocturnal HTN predicts the severity of obstructive sleep apnea [35] and the development of microalbuminuria in diabetic adolescents [36]. Lesser degrees of nocturnal dipping can be associated with LVH in children on dialysis [28]. Isolated abnormalities of sleep BP on ABPM should be taken into consideration when reading an ABPM report. Although there are not enough data on the importance of nocturnal HTN in lower-risk pediatric populations, the definition of a normal ABPM study probably should include normal nocturnal BP and normal dipping.

\section{Blood pressure variability}

Detecting BP variability (BPV), estimated by the standard deviation or coefficient of variance for daytime or night-time readings on $\mathrm{ABPM}$, is straightforward, but not readily done in pediatric practice. Twenty-four-hour BPV is found to be increased in obese children [37] and has been reported to correlate with glomerular filtration rate and albuminuria in young patients with chronic renal insufficiency [38]. Patients with increased BPV have overall greater organ damage and LVMI at follow-up compared with those hypertensive patients in whom BPV is less, but who have the same 24-h BP mean 
values [39]. BPV has been shown to be predictive of stroke and other cardiovascular events in adults, and specific antihypertensive agents have been found to be superior to other drugs in reducing BPV and adverse vascular events [39-41]. Larger prospective pediatric studies are required in which BPV can be assessed as an additional independent factor contributing to cardiovascular risk in HTN, and to determine whether drugs and combinations of drugs that reduce both mean BP and BPV will have a beneficial effect on cardiovascular outcome. Abnormal diurnal variability should be considered important information in assessing HTN in a young patient's ABPM. The duration of action and time of administration of antihypertensive medications are likely to be important considerations in reducing BPV, although lack of sufficient data in children makes this recommendation more difficult to implement.

Accurate assessment of HTN in children is the cornerstone of the better prevention of its deleterious effects. ABPM has become an essential clinical and research tool in day-to-day practice. Despite numerous studies in the literature, there are still gaps in our knowledge of how best to utilize ABPM data. Suláková and Feber [32] have made an important contribution to this rapidly developing field, but much more research is needed to clarify the best approach to the use of the ABPM data set in children. Information on the usefulness of circadian BP control, BP surge (the difference between morning BP and the nadir during sleep) as well as correlations between BP variability and target-organ damage in hypertensive children, is required for the fine-tuning of antihypertensive management. Clinical management recommendations based on outcome studies performed in pediatric patients are surely needed for clinicians who, having diagnosed WCH and masked HTN by ABPM must decide if these results require drug therapy for the prevention of target-organ damage. Currently available normative data [20] are based on mostly Caucasian children with small numbers of shorter children in the database, making the analysis of ABPM studies difficult in children with impaired growth, specifically in children with chronic diseases. Better normative data across different ethnic backgrounds are needed in order to understand the true prevalence of HTN in our communities. However, the advantages of ABPM far outweigh these limitations, and, hence, ABPM has been shown to be a powerful tool for assessing BP in pediatric patients and is now considered by many pediatric nephrologists to be the gold standard for measuring BP in children. The routine use of ABPM among clinicians managing pediatric HTN is sure to grow, hopefully guided by careful trials performed in children.

\section{References}

1. Wang Y, Lobstein T (2006) Worldwide trends in childhood overweight and obesity. Int J Pediatr Obes 1:11-25
2. Kearney PM, Whelton M, Reynolds K, Muntner P, Whelton PK, He J (2005) Global burden of hypertension: analysis of worldwide data. Lancet 365:217-223

3. Din-Dzietham R, Liu Y, Bielo MV, Shamsa F (2007) High blood pressure trends in children and adolescents in national surveys, 1963 to 2002. Circulation 116:1488-1496

4. Bao W, Threefoot SA, Srinivasan SR, Berenson GS (1995) Essential hypertension predicted by tracking of elevated blood pressure from childhood to adulthood: the Bogalusa Heart Study. Am J Hypertens 8:657-665

5. Lewington S, Clarke R, Qizilbash N, Peto R, Collins R, Prospective Studies Collaboration (2002) Age-specific relevance of usual blood pressure to vascular mortality: a meta-analysis of individual data for one million adults in 61 prospective studies. Lancet 360:1903-1913

6. Chobanian AV, Bakris GL, Black HR, Cushman WC, Green LA, Izzo JL Jr, Jones DW, Materson BJ, Oparil S, Wright JT Jr, Roccella EJ, Joint National Committee on Prevention, Detection, Evaluation, and Treatment of High Blood Pressure, National Heart, Lung, and Blood Institute, National High Blood Pressure Education Program Coordinating Committee (2003) Seventh report of the Joint National Committee on Prevention, Detection, Evaluation, and Treatment of High Blood Pressure. Hypertension 42:1206-1252

7. Hansen ML, Gunn PW, Kaelber DC (2007) Underdiagnosis of hypertension in children and adolescents. JAMA 298:874-879

8. Seeman T, Dostalek L, Gilik J (2012) Control of hypertension in treated children and its association with target organ damage. Am J Hypertens 25:389-395

9. Matsuoka S, Kawamura K, Honda M, Awazu M (2002) White coat effect and white coat hypertension in pediatric patients. Pediatr Nephrol 17:950-953

10. Stabouli S, Kotsis V, Toumanidis S, Papamichael C, Constantopoulos A, Zakopoulos N (2005) White-coat and masked hypertension in children: association with target-organ damage. Pediatr Nephrol 20:1151-1155

11. Mitsnefes M, Flynn J, Cohn S, Samuels J, Blydt-Hansen T, Saland J, Kimball T, Furth S, Warady B, Group CKS (2010) Masked hypertension associates with left ventricular hypertrophy in children with CKD. J Am Soc Nephrol 21:137-144

12. Sorof JM, Cardwell G, Franco K, Portman RJ (2002) Ambulatory blood pressure and left ventricular mass index in hypertensive children. Hypertension 39:903-908

13. Mitsnefes MM, Kimball TR, Daniels SR (2003) Office and ambulatory blood pressure elevation in children with chronic renal failure. Pediatr Nephrol 18:145-149

14. ESCAPE Trial Group, Wühl E, Trivelli A, Picca S, Litwin M, Peco-Antic A, Zurowska A, Testa S, Jankauskiene A, Emre S, Caldas-Afonso A, Anarat A, Niaudet P, Mir S, Bakkaloglu A, Enke B, Montini G, Wingen AM, Sallay P, Jeck N, Berg U, Caliskan S, Wygoda S, Hohbach-Hohenfellner K, Dusek J, Urasinski T, Arbeiter K, Neuhaus T, Gellermann J, Drozdz D, Fischbach M, Möller K, Wigger M, Peruzzi L, Mehls O, Schaefer F (2009) Strict blood-pressure control and progression of renal failure in children. N Engl J Med 361:1639-1650

15. Balzano R, Lindblad YT, Vavilis G, Jogestrand T, Berg UB, Krmar RT (2011) Use of annual ABPM, and repeated carotid scan and echocardiography to monitor cardiovascular health over nine yr in pediatric and young adult renal transplant recipients. Pediatr Transplant 15:635-641

16. Swartz SJ, Srivaths PR, Croix B, Feig DI (2008) Costeffectiveness of ambulatory blood pressure monitoring in the initial evaluation of hypertension in children. Pediatrics 122:1177-1181

17. Urbina E, Alpert B, Flynn J, Hayman L, Harshfield GA, Jacobson M, Mahoney L, McCrindle B, Mietus-Snyder M, Steinberger J, 
Daniels S, American Heart Association Atherosclerosis, Hypertension, and Obesity in Youth Committee (2008) Ambulatory blood pressure monitoring in children and adolescents: recommendations for standard assessment: a scientific statement from the American Heart Association Atherosclerosis, Hypertension, and Obesity in Youth Committee of the council on cardiovascular disease in the young and the council for high blood pressure research. Hypertension 52:433-451

18. Koshy S, Macarthur C, Luthra S, Gajaria M, Geary D (2005) Ambulatory blood pressure monitoring: mean blood pressure and blood pressure load. Pediatr Nephrol 20:1484-1486

19. National High Blood Pressure Education Program Working Group on High Blood Pressure in Children and Adolescents (2004) The fourth report on the diagnosis, evaluation, and treatment of high blood pressure in children and adolescents. Pediatrics 114:555-576

20. Soergel M, Kirschstein M, Busch C, Danne T, Gellermann J, Holl R, Krull F, Reichert H, Reusz GS, Rascher W (1997) Oscillometric twenty-four-hour ambulatory blood pressure values in healthy children and adolescents: a multicenter trial including 1141 subjects. J Pediatr 130:178-184

21. Wühl E, Witte K, Soergel M, Mehls O, Schaefer F, German Working Group on Pediatric H (2002) Distribution of 24-h ambulatory blood pressure in children: normalized reference values and role of body dimensions. J Hypertens 20:1995-2007

22. Gellermann J, Kraft S, Ehrich JH (1997) Twenty-four-hour ambulatory blood pressure monitoring in young children. Pediatr Nephrol 11:707-710

23. Lurbe E, Sorof JM, Daniels SR (2004) Clinical and research aspects of ambulatory blood pressure monitoring in children. J Pediatr 144:7-16

24. White WB, Dey HM, Schulman P (1989) Assessment of the daily blood pressure load as a determinant of cardiac function in patients with mild-to-moderate hypertension. Am Heart J 118:782-795

25. Strandberg TE, Salomaa VV, Vanhanen HT, Pitkala K, Miettinen TA (2002) Isolated diastolic hypertension, pulse pressure, and mean arterial pressure as predictors of mortality during a followup of up to 32 years. J Hypertens 20:399-404

26. Franklin SS, Pio JR, Wong ND, Larson MG, Leip EP, Vasan RS, Levy D (2005) Predictors of new-onset diastolic and systolic hypertension: the Framingham Heart Study. Circulation 111:1121-1127

27. Flynn JT (2002) Differentiation between primary and secondary hypertension in children using ambulatory blood pressure monitoring. Pediatrics 110:89-93

28. Chaudhuri A, Sutherland SM, Begin B, Salsbery K, McCabe L, Potter D, Alexander SR, Wong CJ (2011) Role of twenty-four-hour ambulatory blood pressure monitoring in children on dialysis. Clin J Am Soc Nephrol 6:870-876

29. Flynn JT (2011) Ambulatory blood pressure monitoring in children: imperfect yet essential. Pediatr Nephrol 26:2089-2094
30. Badin J, Boulain T, Ehrmann S, Skarzynski M, Bretagnol A, Buret J, Benzekri-Lefevre D, Mercier E, Runge I, Garot D, Mathonnet A, Dequin PF, Perrotin D (2011) Relation between mean arterial pressure and renal function in the early phase of shock: a prospective, explorative cohort study. Crit Care 15:R135

31. Cnossen JS, Vollebregt KC, de Vrieze N, ter Riet G, Mol BW, Franx A, Khan KS, van der Post JA (2008) Accuracy of mean arterial pressure and blood pressure measurements in predicting pre-eclampsia: systematic review and meta-analysis. BMJ 336:1117-1120

32. Suláková T, Feber J (2013) Should mean arterial pressure be included in the definition of ambulatory hypertension in children? Pediatr Nephrol doi:10.1007/s00467-012-2382-7

33. Liu M, Takahashi H, Morita Y, Maruyama S, Mizuno M, Yuzawa Y, Watanabe M, Toriyama T, Kawahara H, Matsuo S (2003) Nondipping is a potent predictor of cardiovascular mortality and is associated with autonomic dysfunction in haemodialysis patients. Nephrol Dial Transplant 18:563-569

34. McGlothan KR, Wyatt RJ, Ault BH, Hastings MC, Rogers T, DiSessa T, Jones DP (2006) Predominance of nocturnal hypertension in pediatric renal allograft recipients. Pediatr Transplant 10:558-564

35. Li AM, Au CT, Sung RY, Ho C, Ng PC, Fok TF, Wing YK (2008) Ambulatory blood pressure in children with obstructive sleep apnoea: a community based study. Thorax 63:803-809

36. Lurbe E, Redon J, Kesani A, Pascual JM, Tacons J, Alvarez V, Batlle D (2002) Increase in nocturnal blood pressure and progression to microalbuminuria in type 1 diabetes. $\mathrm{N}$ Engl $\mathrm{J}$ Med 347:797-805

37. Sorof JM, Poffenbarger T, Franco K, Bernard L, Portman RJ (2002) Isolated systolic hypertension, obesity, and hyperkinetic hemodynamic states in children. J Pediatr 140:660-666

38. Wühl E, Hadtstein C, Mehls O, Schaefer F, Group ET (2005) Ultradian but not circadian blood pressure rhythms correlate with renal dysfunction in children with chronic renal failure. J Am Soc Nephrol 16:746-754

39. Frattola A, Parati G, Cuspidi C, Albini F, Mancia G (1993) Prognostic value of 24-h blood pressure variability. J Hypertens 11:1133-1137

40. Poortvliet RK, Ford I, Lloyd SM, Sattar N, Mooijaart SP, de Craen AJ, Westendorp RG, Jukema JW, Packard CJ, Gussekloo J, de Ruijter W, Stott DJ (2012) Blood pressure variability and cardiovascular risk in the PROspective Study of Pravastatin in the Elderly at Risk (PROSPER). PLoS One 7:e52438

41. Zhang Y, Agnoletti D, Safar ME, Blacher J (2011) Effect of antihypertensive agents on blood pressure variability: the Natrilix SR versus candesartan and amlodipine in the reduction of systolic blood pressure in hypertensive patients (X-CELLENT) study. Hypertension 58:155-160 